\title{
Conf- $940630--52$
}

\author{
UCRL-JC-116030
}

PREPRINT

\section{Target Injection Methods for Inertial Fusion Energy}

\author{
Ronald W. Petzoldt \\ Ralph W. Moir
}

This paper was prepared for submittal to the

American Nuclear Society

11th Topical Meeting on the Technology of Fusion Energy

New Orleans, Louisiana

June 19-23, 1994

June 1994

This is a preprint of a paper intended for publication in a journal or proceedings. Since changes may be made before publication, this preprint is made available with the understanding that it will not be cited or reproduced without the permission of the author.

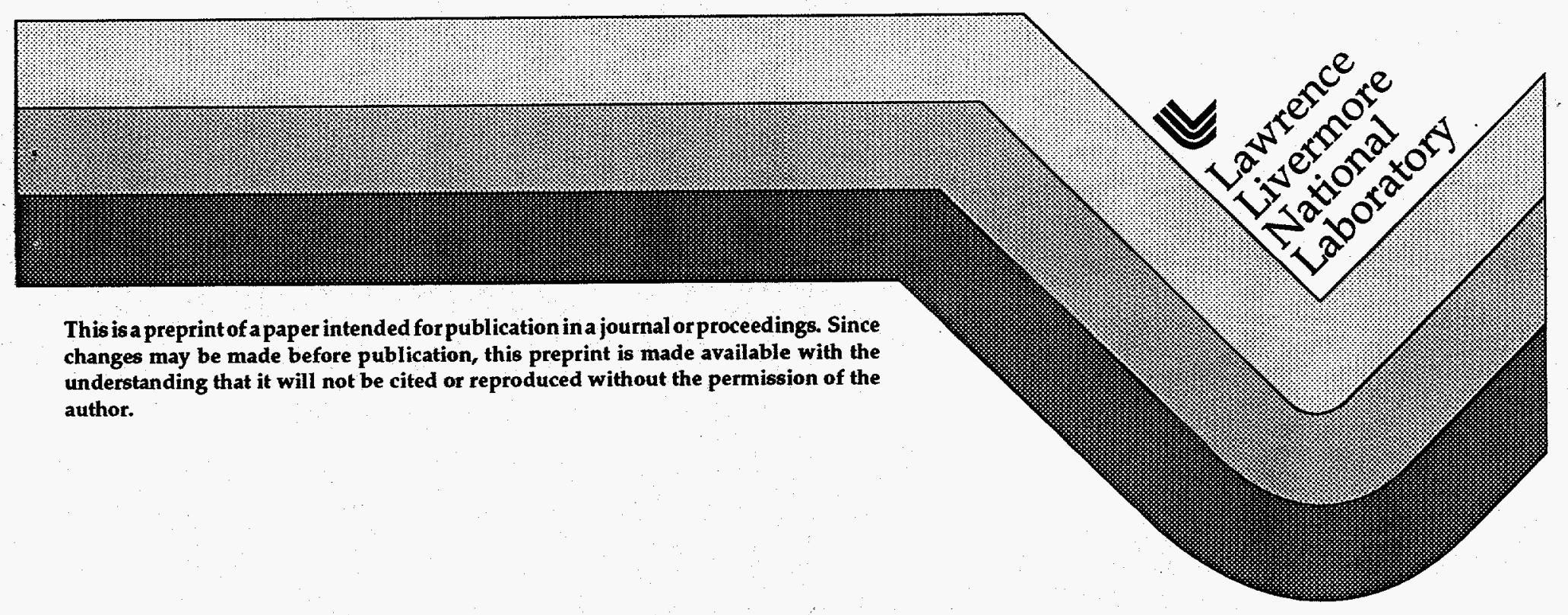


This document was prepared as an account of work sponsored by an agency of the United States Government. Neither the United States Government nor the University of California nor any of their employees, makes any warranty, express or implied, or assumes any legal liability or responsibility for the accuracy, completeness, or usefulness of any information, apparatus, product, or process disclosed, or represents that its use would not infringe privately owned rights. Reference herein to any specific commercial products, process, or service by trade name, trademark, manufacturer, or otherwise, does not necessarily constitute or imply its endorsement, recommendation, or favoring by the United States Government or the University of California. The views and opinions of authors expressed herein do not necessarily state or reflect those of the United States Government thereof, and shall not be used for advertising or product endorsement purposes. 


\section{DISCLAIMER}

Portions of this document may be illegible in electronic image products. Images are produced from the best available original document. 


\section{TARGET INJECTION METHODS FOR INERTIAL FUSION ENERGY}

\author{
Ronald W. Petzoldt \\ University of California \\ Lawrence Livermore National Laboratory \\ P. O. Box 5511 \\ Livermore, CA 94551 \\ (510) 422-9860
}

\section{ABSTRACT}

We have studied four methods to inject IFE targets: the gas gun, electrostatic accelerator, induction accelerator, and rail gun. ${ }^{*}$ We recommend a gas gun for indirect drive targets because they can support a gas pressure load on one end and can slide along the gun barrel without damage. With the gas gun, the amount of gas required for each target (about 10 to $100 \mathrm{mg}$ ) is acceptable; for other types of targets, a sabot would be necessary. A cam and poppet valve arrangement is recommended for gas flow control. An electrostatic accelerator is attractive for use with lightweight spherical direct drive targets. Since there is no physical contact between the target and the injector, there will be no wear of either component during the injection process. An induction accelerator has an advantage of no electrical contact between the target and the injector. Physical contact is not even necessary, so the wear should be minimal. It requires a cylindrical conductive target sleeve which is a substantial added mass. A rail gun is a simpler device than an electrostatic accelerator or induction accelerator. It requires electrical contact between the target and the rails and may have a significant wear rate. The wear in a vacuum could be reduced by use of a solid lubricant such as $\mathrm{MoS}_{2}$. The total required accuracy of target injection, tracking and beam pointing of $\pm 0.4 \mathrm{~mm}$ appears achievable but will require development and experimental verification.

\section{INTRODUCTION}

As indicated in Fig.1, a target injector is an important component of an inertial fusion energy power plant. The approximate performance parameters include the following. ${ }^{1}$ Injection speeds must be of order $100 \mathrm{~m} / \mathrm{s}$. For reasonable gun lengths,

\author{
Ralph W. Moir \\ University of California \\ Lawrence Livermore National Laboratory \\ P. O. Box 5511 \\ Livermore, CA 94551 \\ (510) 422-9860
}

the required target acceleration is of order 1,000 to $10,000 \mathrm{~m} / \mathrm{s}^{2}$. Target placement in the reaction chamber must be about $\pm 0.2 \mathrm{~mm}$. If the target placement is not repeatable to this accuracy, then the driver beams can be actively pointed to meet the target. For some targets, an axis of symmetry must be maintained to about $\pm 1^{\circ}$. The repetition rate must be several targets per second ( 6 for HYLIFE-II).

There are many methods of target injection that may be effective in delivering targets to meet the above parameters. The top injection candidates are the electrostatic accelerator, gas gun, rail gun, induction accelerator, and ferromagnetic accelerator. The type of injection mechanism chosen may be different for different power plant and target designs. The injection mechanism for a direct drive target may well be different than the mechanism for an indirect drive target. References $2-4$ all recommend gas gun target injection for targets with removable sabots or indirect drive targets. Reference 5 compares the gas gun and ferromagnetic accelerator both using sabots. Reference 6 recommends gas gun for indirect drive and the ferromagnetic accelerator with a sabot for direct drive. The ferromagnetic design uses a traveling magnetic field gradient to exert a force on a ferromagnetic cylinder which is placed inside the sabot. This injection method is described in Ref. 2 .

The performance and cost of target injection systems are not well enough known to make quantitative target injector selection decisions. However, there are substantial qualitative differences that do indicate a preferred injector for various kinds of targets. The leading injection methods (except ferromagnetic acceleration) are discussed in the following sections. Table 1 summarizes the advantages and disadvantages of these methods.

\footnotetext{
* We also conducted related studies (which will be reported in the first author's Ph.D. thesis) of indirect drive capsule membrane support with fuel and membrane stress calculations, target steering, target injection, tracking, and beam pointing requirements.
}

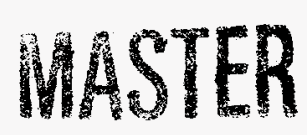




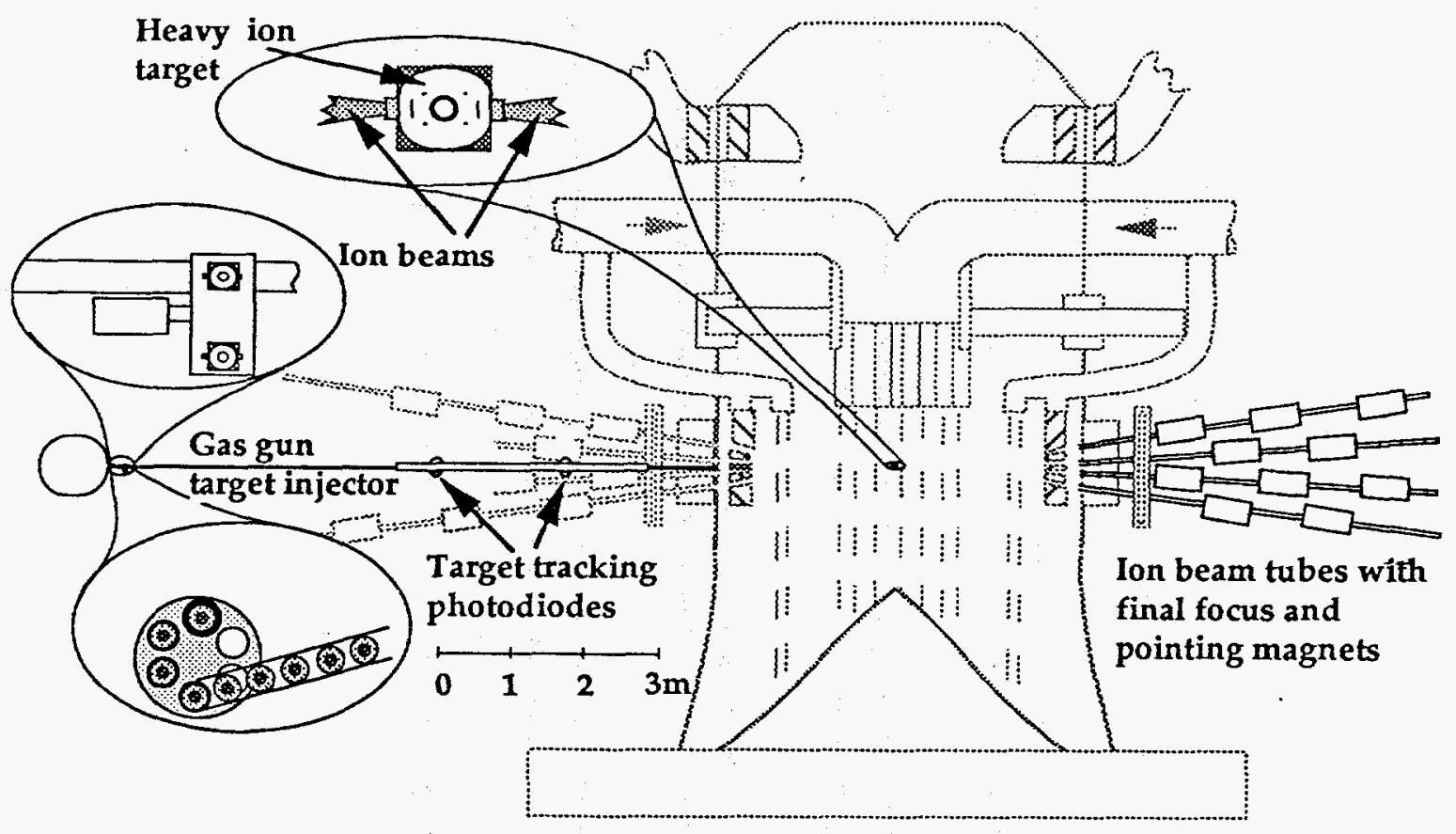

Figure 1. Inertial fusion energy reaction chamber with target injector and final part of driver beams.

Table 1. Advantages and disadvantages of leading injection methods.

\begin{tabular}{l|l|l}
\hline \hline $\begin{array}{l}\text { Injection } \\
\text { Method }\end{array}$ & Advantages & Disadvantages \\
\hline Gas gun & $\begin{array}{l}\text { - Simple } \\
\text { - Low risk of failure } \\
\text { - Low cost }\end{array}$ & $\begin{array}{l}\text { - Injects gas into vacuum chamber } \\
\text { requiring additional vacuum pumping }\end{array}$ \\
\hline $\begin{array}{l}\text { Electrostatic } \\
\text { accelerator }\end{array}$ & $\begin{array}{l}\text { - Requires no sabot } \\
\text { - No wear of target or injector }\end{array}$ & $\begin{array}{l}\text { - Limited propulsive force } \\
\text { - Difficult to control of target position }\end{array}$ \\
\hline Rail gun & - Simple & - Probably good speed control \\
\hline $\begin{array}{l}\text { Induction } \\
\text { accelerator }\end{array}$ & $\begin{array}{l}\text { Possibly severe wear } \\
\text { - Conducting armature material must be added to } \\
\text { target }\end{array}$ \\
\hline \hline
\end{tabular}




\section{GAS GUN}

A gas gun uses compressed gas (perhaps helium) to propel the target down a cylindrical barrel toward the reaction chamber. Some new concepts for a gas gun are indicated in Fig. 2. The gas flow is controlled by a rotating cam and poppet valve arrangement allowing rapid (about $1 \mathrm{~ms}$ ) and reliable operation similar to an internal combustion engine. Reloading of the gun is accomplished via a revolver mechanism. A potential source of inaccuracy with a gas gun is gas flowing past the target after the target moves out of the barrel. This effect could be minimized by putting openings near the end of the gun barrel through which much of the gas can escape. Most of the gas escapes through the vents before it has a chance to disrupt the target trajectory and the gas may be differentially pumped prior to entering the reaction chamber.

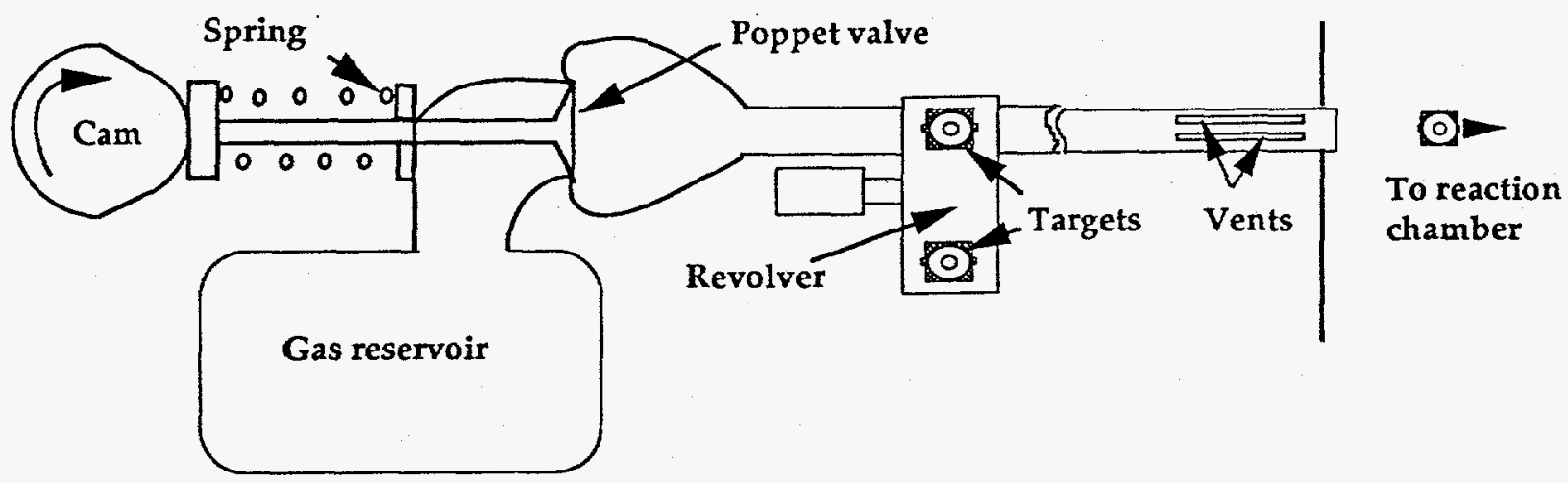

Figure 2. Gas gun target injector with vents for the gas to escape.

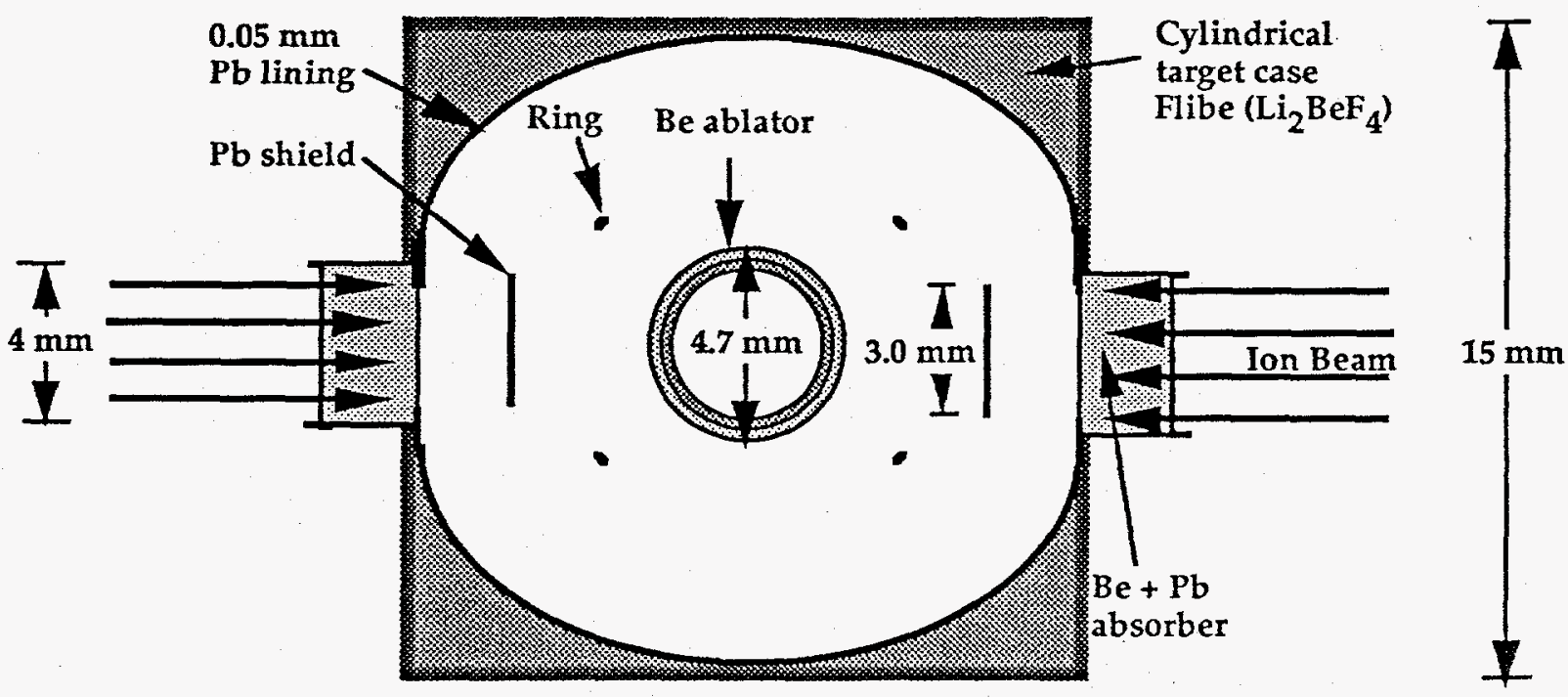

Figure 3. Heavy ion driven indirect drive target. ${ }^{7}$ 
The amount of gas that would be required per shot can be estimated as follows. We use the target designed by $\mathrm{Ho}$ and reported in these proceedings. This target, to which we have added a cylindrical target case for injection purposes, is shown in Fig. 3. The mass of the basic target is about $0.5 \mathrm{~g}$, to this we add an additional $2 \mathrm{~g}$ of Flibe ( $\mathrm{Li}_{2} \mathrm{BeF}_{4}$ ). Assume this $2.5 \mathrm{~g}, 7.5 \mathrm{~mm}$ radius target must be accelerated to a speed of $100 \mathrm{~m} / \mathrm{s}$ at a rate of $1000 \mathrm{~m} / \mathrm{s}^{2}$ with room temperature helium. The required gas pressure is given by

$$
\begin{aligned}
& \text { Pressure }=\frac{\text { Force }}{\text { Area }}=\frac{\mathrm{ma}}{\pi \mathrm{r}^{2}}=\frac{(0.0025 \mathrm{~kg})\left(1000 \mathrm{~m} / \mathrm{s}^{2}\right)}{\pi(0.0075 \mathrm{~m})^{2}} \\
& =14 \mathrm{kPa}(2.1 \mathrm{psi})
\end{aligned}
$$

The volume of the barrel is given by

$$
\begin{aligned}
& \text { Volume }=\text { Length } \times \text { Area }=\frac{v^{2}}{2 a} \pi r^{2} \\
& =\frac{(100 \mathrm{~m} / \mathrm{s})^{2}}{2\left(1000 \mathrm{~m} / \mathrm{s}^{2}\right)} \pi(0.0075 \mathrm{~m})^{2}=8.8 \times 10^{-4} \mathrm{~m}^{3}
\end{aligned}
$$

The number of moles is obtained from the ideal gas law

$$
\begin{aligned}
& \mathrm{n}=\frac{\mathrm{PV}}{\mathrm{RT}}=\frac{14000 \mathrm{~Pa}\left(8.8 \times 10^{-4} \mathrm{~m}^{3}\right)}{8.31 \mathrm{~J} \mathrm{deg}^{-1} \mathrm{~mole}(293 \mathrm{~K})}=5.1 \times 10^{-3} \mathrm{~mole} \\
& \left(3 \times 10^{21} \text { atoms or } 20 \mathrm{mg}\right)
\end{aligned}
$$

If this gas were dispersed through a $100 \mathrm{~m}^{3}$ reaction chamber there would be $3 \times 10^{13}$ atoms $/ \mathrm{cm}^{3}$. (A far lower density will appear in the reaction chamber because pumping will be accomplished in the target injection chamber and a shutter can be put near the chamber to minimize gas entry). This number density is of the same order as the maximum density through which ion beams are expected to propagate (some power plant designs rely on channel transport and allow over $10^{16}$ atoms $/ \mathrm{cm}^{3}$ ). It may be necessary to use a lower temperature gas to limit target heating. If so, a proportionally larger mass of gas would be required (i.e., about $100 \mathrm{mg}$ ). This gas must be pumped from any power plant that uses gas gun injection. The allowed steady state vacuum will depend on the particular power plant design. The most efficient differential pumping would be near the injector upstream of the reaction chamber.

It should be noted that for a $400 \mathrm{MJ}$ fusion micro explosion, about $1 \mathrm{mg}$ of helium is produced and several milligrams of other gases such as deuterium and tritium are released. These gases must be removed from the reaction chamber and reprocessed. Therefore, it should not pose a problem if less than $1 \mathrm{mg}$ of helium from a gas gun enters the reaction chamber.

For targets which require sabots, the sabots could adversely affect target injection accuracy. A potential cause of inaccuracy occurs when the sabot separates from the target. Suppose the sabot splits into two halves and one half applies a frictional force equal to the targets weight for a distance of $1 \mathrm{~mm}$. The target would then be given an uncontrollable velocity component of $0.14 \mathrm{~m} / \mathrm{s}$. If the target coasts for $0.1 \mathrm{~s}$, an inaccuracy of $14 \mathrm{~mm}$ would occur.

To estimate the accuracy that can be expected, a comparison can be made with match quality air rifles. Air rifles are capable of firing test groups subtending $1 / 2 \mathrm{~min}(0.15 \mathrm{mrad})$ of angle at the standard 10 m range. ${ }^{8}$ This is a $1.5 \mathrm{~mm}$ spread at 10 $m$. This accuracy should be met, or exceeded, firing through vacuum into a reaction chambër. If the accuracy can be improved (to $\pm 0.2 \mathrm{~mm}$ ) active target and beam steering could be avoided.

The gas gun target injection method is recommended for indirect drive targets because it is a simple, reliable device and the required gas pumping is manageable.

\section{ELECTROSTATIC ACCELERATOR}

Electrostatic levitation has been studied at LLNL. ${ }^{9-11}$ The process was called electrostatic levitation because the emphasis was on suspending the targets rather than accelerating them. Small ( 800 $\mu \mathrm{m}$ diameter) capsules were stably levitated in air for several days and transported in air with speeds of $10^{-4}$ $\mathrm{m} / \mathrm{s}$ to $0.1 \mathrm{~m} / \mathrm{s}^{7}$ As shown in Fig. 4, the target capsules are given an electrical charge and suspended between quadrupole rails. As described in Ref. 11, the oscillating quadrupole field provides a centering force to dynamically confine the target. Target position monitoring with active feedback could eliminate the need for an oscillating quadrupole field. A DC field can be added to counteract the effects of gravity. Accelerating electrodes are installed to provide the required electric field for target acceleration. There will be many accelerating electrodes in the target injector. If they are sequentially connected to the phases of a three phase power supply there will be a traveling electric field moving down the axis of the injector. The speed of the accelerating field motion is proportional to the product of the electrode spacing and the power supply frequency. The accelerating electrode spacing or the power supply frequency can be adjusted to synchronize the field speed to the target speed. 


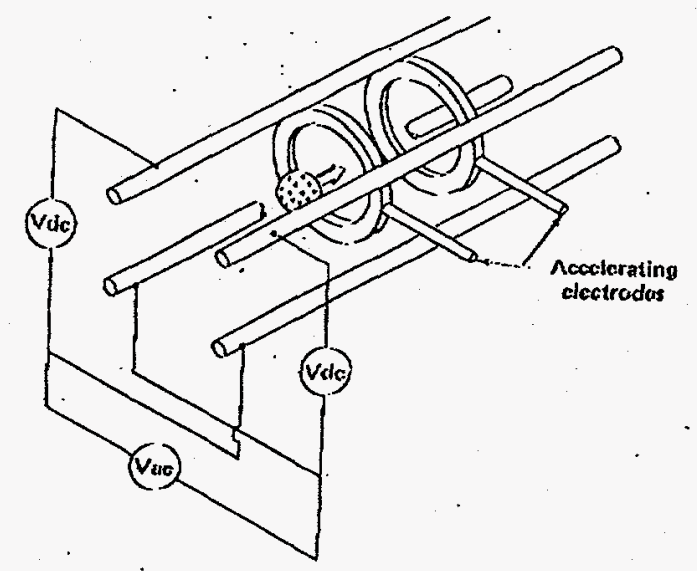

Figure 4. The target is dynamically confined between quadrapole rails. Alternatively, active feedback field control could be used. A DC field is applied to counteract gravity. Accelerating electrodes provide a traveling electric field to accelerate the target (Ref. $10)$.

The mass of a capsule that can be electrostatically accelerated is limited by the charge on the target and the externally applied electric field, which in turn are limited by vacuum sparking. Vacuum sparking can be initiated by field emission or field ionization. Field emission is due to tunneling of electrons through the potential barrier at the surface of the cathode under the influence of high electrostatic fields. Typically, fields of 3 to $6 \times 10^{9}$ $\mathrm{V} / \mathrm{m}$ are required for large scale field emission. ${ }^{12}$ Field ionization is caused by electrons tunneling away from adsorbed molecules on the surface of the anode, causing the ions to be released from the anode surface. Large scale field ionization requires even higher fields of 2 to $5 \times 10^{10} \mathrm{~V} / \mathrm{m} .12$ Vacuum sparking can be caused by a cascade effect with electric fields far below those required for large scale field emission. ${ }^{13}$ The cascade process assumes a localized evolution of gas from the cathode surface resulting from a few gas ions impinging on the cathode surface resulting in the release of adsorbed gas molecules and electrons. For a cascade to occur, electrons emitted from a cathode must have sufficient energy to cause ionization of gas particles enroute to the anode which in turn cause further release of electrons and gases from the cathode. It has been empirically determined that vacuum sparking normally does not occur if the following condition is satisfied ${ }^{13}$

$$
\operatorname{VE}^{2}\left\{\exp \left(-\frac{1.7 \times 10^{7}}{\mathrm{E}}\right)\right\} \leq 1.8 \times 10^{18}
$$

Here $V$ is the potential (maximum energy of a charged particle at the electrode surface in $\mathrm{eV}$ prior to the spark) in volts and $E$ is the electric field at the surface of the cathode in volts per meter. Equation (4) is applicable for typical materials without special treatment and is known as Kilpatrick's criterion. The potential and electric fields of a charged sphere are given by

$$
E=\frac{q}{4 \pi \varepsilon_{0} r^{2}} \text { and } V=\frac{q}{4 \pi \varepsilon_{0} r}
$$

where $q$ is the charge in coulombs and $r$ is the radius in meters. Equations (4) and (5) can be combined to estimate the maximum charge that can normally be stored on a sphere of a given radius. For example, a 3 $\mathrm{mm}$ radius spherical cathode could sustain a charge of about $1.3 \times 10^{-8}$ coulombs. This charge gives a field of $1.3 \times 10^{7} \mathrm{~V} / \mathrm{m}$ and a potential of $3.9 \times 10^{4} \mathrm{~V}$. Assuming an external field of $10^{6} \mathrm{~V} / \mathrm{m}^{-}$could be applied, the force $F$ on the sphere would be given by

$F=E q=\left(10^{6} \mathrm{~V} / \mathrm{m}\right)\left(1.3 \times 10^{-8} \mathrm{Coul}\right)=0.013 \mathrm{~N}$.

(The calculated electric field of $1.3 \times 10^{7} \mathrm{~V} / \mathrm{m}$ is much greater than the external field of $10^{6} \mathrm{~V} / \mathrm{m}$ so using the electric field of the sphere in Kilpatrick's criterion is approximately correct. One should verify that the electric fields at the surface of the external electrodes are not higher than the field on the sphere and consider the effect of the external field on the total potential difference which could cause sparking to occur.) Since $m=\frac{F}{a}$, the maximum mass $m$ of such a sphere would be limited by this force and the required acceleration. If $1000 \mathrm{~m} / \mathrm{s}^{2}$ acceleration is required, the maximum mass would be $0.013 \mathrm{~g}$, which is a little less than a typical direct drive target. Since field ionization requires larger fields than field emission, larger masses could be accelerated if the sphere were charged positive rather than negative. ${ }^{12}$ In Ref. 9 two plates were separated by $1 \mathrm{~cm}$ with a potential difference between them. The small $800 \mu \mathrm{m}$ diameter capsules oscillated between the plates, exchanging charge at each plate. A small hole was placed in one plate through which the capsules would occasionally be propelled down the axis of the accelerator electrodes. The charge $q$ transferred by this method is given by $q=6.6 \pi \varepsilon_{0} r^{2} \mathrm{E}$, where $r$ is the capsule radius and $E$ is the electric field between the plates. ${ }^{14}$ For power plant target injection purposes, this procedure should be modified to control the timing of targets entering the injector and to maximize the positive charge placed on the target without vacuum sparking. As shown in Fig. 5, the target can be placed on a convex anode which is energized to charge the target and to start its motion into the accelerator. Using a relatively small radius anode should reduce the cathode field allowing 
greater charge to be placed on the target without vacuum sparking. It remains to be experimentally verified that adequate acceleration of reactor sized targets can be achieved in this manner.

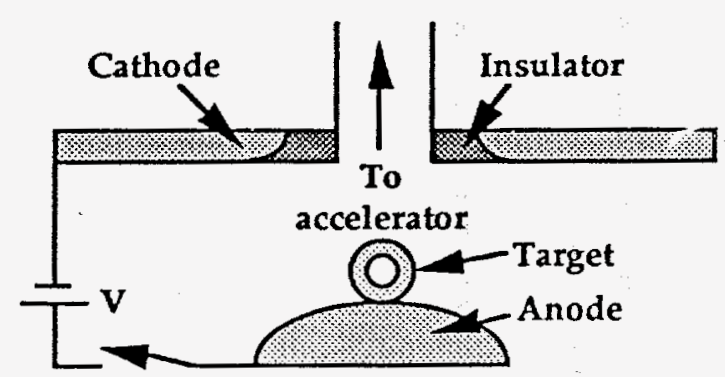

Figure 5. The target is placed on the anode which is then energized transferring charge to the conducting target surface. The positively charged target is then electrostatically repelled toward the accelerator.

Electrostatic acceleration has no sliding contact between the target and the accelerator. No contact implies no wear on the injector, and helps maintain the smooth surface finish of spherical direct drive targets. Vacuum electrical breakdown may be a problem, particularly for more massive or nonspherical targets. Electrostatic acceleration shows promise primarily for accelerating low mass, spherically symmetric targets.

\section{RAIL GUN}

The simplest electromagnetic device to accelerate a projectile is a rail gun. A rail gun is schematically illustrated in Fig. 6. Current flows from the power supply to one rail of the rail gun through conducting material attached to the target and back through the opposite rail to the power supply. (Many rail guns use a plasma arc behind the projectile instead of a solid conducting material. However, plasma armature rail guns have high erosion at low velocities and probably would not be suitable for target injection.) The current flowing through the rails produces a magnetic field between the rails. The interaction between this field and the current flowing through the projectile produces a force that propels the projectile down the rail gun barrel.

The amount of-current required can be estimated using a simple model. Assume that the average magnetic field between the rails is equal to the magnetic field midway between two long cylindrical conductors. Two views of the assumed conductors together with their assumed currents and fields are shown in Fig. 7. The spacing between the conductors is $2 r$. The magnetic field $B$ between the conductors for a current $I$ is given by

$$
\mathrm{B}=\frac{\mu_{0} I}{\pi_{\mathrm{r}}}
$$

where $\mu_{\mathrm{O}}=4 \pi \times 10^{-7} \mathrm{~kg} \mathrm{~m} \mathrm{~s}^{-2} \mathrm{~A}^{-2}$. Assuming that the average distance that the current flows through this field is $r$, the force $F$ exerted on the conductor is given by

$$
F=\operatorname{IrB}=\frac{\mu_{0} I^{2}}{\pi}=4 \times 10^{-3} 1^{2}
$$

Solving for current gives

$$
\mathrm{I}=\sqrt{2.5 \times 10^{6} \mathrm{~F}}=\sqrt{2.5 \times 10^{6} \mathrm{ma}}
$$

For example, the target from Fig. 3 with Flibe replaced by lithium has a mass of $1 \mathrm{~g}$ and radius of $7.5 \mathrm{~mm}$. To accelerate this target at $1000 \mathrm{~m} / \mathrm{s}^{2}$ requires around $1.6 \mathrm{kA}$ and produces a field of 0.08 tesla. Since the resulting field is rather low, the required current could be reduced considerably by applying an external magnetic field of 1 tesla. Then for the same acceleration, the current would be about 130 amps. This reduced current requirement would greatly reduce the $R^{2} R$ heating of the target and rails by more than two orders of magnitude. A magnetic field of order 1 tesla can easily be applied using permanent magnets.

Maintaining good electrical contact between the rails and the armature (target) in a vacuum without excessive wear may be difficult. Most conducting materials wear much faster in a vacuum than in normal atmosphere. In a vacuum the oxide layers on metals are removed causing increased friction and rapid wear. ${ }^{15}$ Graphite wears much faster in a vacuum than when three Torr of water vapor or atmospheric pressure of oxygen is present. ${ }^{16}$

Lubrication can reduce the wear rate substantially. The $\mathrm{MoS}_{2}$ in electrical brushes made of $88 \% \mathrm{Ag}: 12 \% \mathrm{MoS}_{2}$ provides lubrication in vacuum conditions. ${ }^{17}$ Contact lubrication experiments have typically been done with lower currents and sliding speeds than are required for a target injector. Further study is required to determine the feasibility of providing lubrication for this application. 

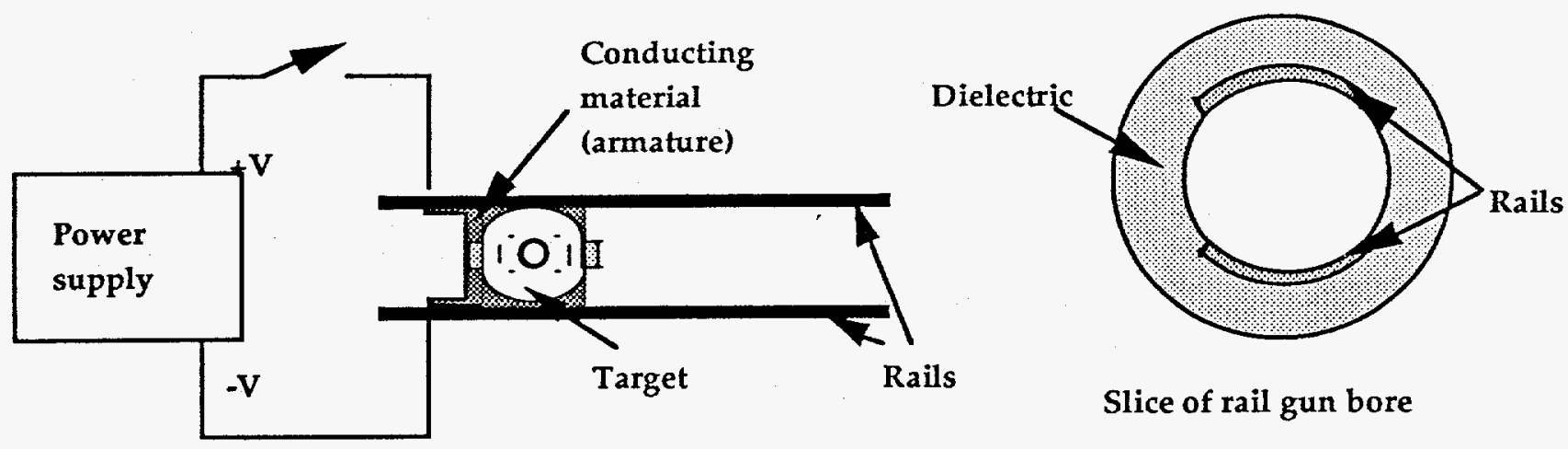

Slice of rail gun bore

Figure 6. Schematic of solid armature rail gun for target injection. The cylindrical shape of a typical rail gun bore is shown (other shapes may be used).
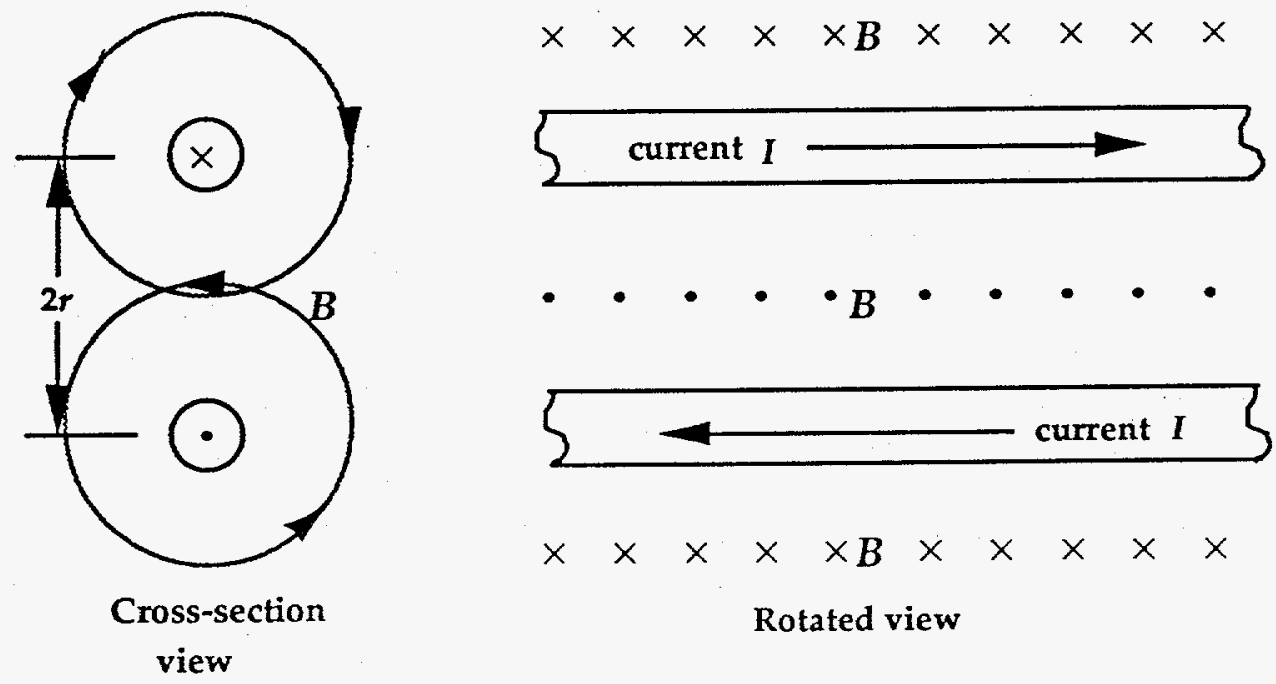

Rotated view

Figure 7. Simplified model to estimate the currents and fields associated with a rail gun target injector. The rails are modeled as cylindrical conductors, and the magnetic field is calculated for a point midway between the conductors. (An $x$ indicates into the page. $A \cdot$ indicates out of the page.)

The decision must be made whether to send the armature into the reaction chamber with the rest of the target. For direct drive targets, the capsule would have to be separated from the armature. For indirect drive targets the separation may be optional. The armature could be slowed down prior to leaving the gun barrel by applying a current from the muzzle end of the injector. The target, if not held to the armature, could separate from the armature and proceed toward the reaction chamber. This separation of the target from the armature may adversely effect target injection accuracy. The armatures could be collected for reuse. If the conducting armatures do enter the reaction chamber, compatible materials must be used for the armature. For example, reactors using Flibe $\left(\mathrm{Li}_{2} \mathrm{BeF}_{4}\right)$ could use a few hundred milligrams of $\mathrm{Li}$ for the armature as was done in our example problem. 


\section{INDUCTION ACCELERATOR}

Induction accelerators are more complicated than rail guns. However, they have the significant advantage of not requiring any electrical contact between the injector and the target.

D. G. Elliott provides a good introduction to traveling wave induction launchers. ${ }^{18}$ The injector consists of many closely spaced circular coils. The armature (target) contains a cylindrical conducting ring. The coils are sequentially energized to produce a magnetic field with a radial component that travels down the injector with speed $U_{s}$. Figure 8 shows the geometry with the coils.

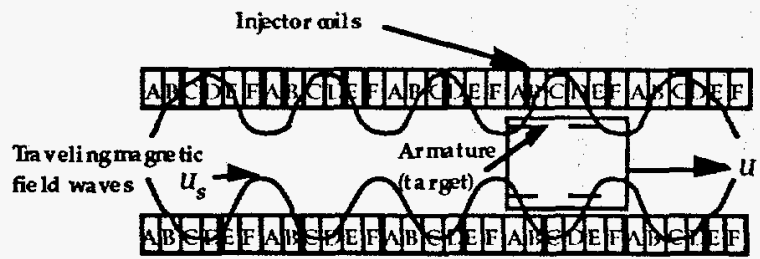

Figure 8. A 6-phase induction accelerator.

The traveling magnetic field passing through the armature causes potential difference and current flow in the armature. This field can be difficult to calculate. It is due to the currents flowing in the coils and the induced current in the armature. The calculations can be simplified using the current sheet approximation. ${ }^{19}$ The current in the coils is modeled by a surface current $K_{b}$ at effective radius $r_{b}(\mathrm{~A} / \mathrm{m})$. $K_{b}$ is assumed to be a traveling sinusoidal wave of the form in phasor notation

$$
K_{\mathrm{b}}=\mathrm{K}_{\mathrm{b}} \cos (\omega \mathrm{t}-\beta \mathrm{z}) \theta_{0}=\operatorname{Re}\left[\underline{\mathrm{K}}_{\mathrm{b}} \mathrm{e}^{\mathrm{i}(\omega \mathrm{t}-\beta \mathrm{z})}\right] \theta_{0}
$$

where $\underline{K}_{b}$ is the complex surface current density, $\omega$ is the angular frequency, and $\beta$ is the wave number. The induced sleeve current $\underline{K}_{S}$ is then given by ${ }^{18}$

$$
\underline{\mathrm{K}}_{s}=\frac{-s}{\sqrt{s_{\mathrm{c}}^{2}+s^{2}}}\left[\frac{\mathrm{r}_{\mathrm{b}} \mathrm{K}_{1}\left(\beta \mathrm{r}_{\mathrm{b}}\right)}{\mathrm{r}_{\mathrm{b}} \mathrm{K}_{1}\left(\beta \mathrm{r}_{\mathrm{s}}\right)}\right] \underline{\mathrm{K}}_{\mathrm{b}} \angle \phi
$$

where $s$ is the slip between the wave velocity $U_{S}$ and the sleeve speed $U, s=\left(U_{s} U\right) / U_{S} . K_{1}$ is the first order modified bessel function of the second kind. $\phi$ is the phase shift between the sleeve current sheet and the barrel current sheet and is given by

$$
\phi=\tan ^{-1} \frac{S_{\mathrm{c}}}{\mathrm{S}}
$$

$s_{c}$ is the critical slip at which the force is maximized for a given barrel current.

$$
S_{C}=\frac{1}{\mu_{0} \sigma_{s} a_{s} U_{s} \beta r_{s} K_{1}\left(\beta r_{s}\right) I_{1}\left(\beta r_{s}\right)}
$$

where $\mu_{\mathrm{o}}$ is permeability of air, $a_{s}$ is the sleeve thickness, and $I_{1}$ is the first order modified bessel function of the first kind.

The average force per unit area on the sleeve $F_{z}$ is given by ${ }^{19}$

$$
F_{z}=\frac{S S_{c}}{S_{c}^{2}+S^{2}} \frac{\mu_{0} \beta r_{b}^{2} K_{1}^{2}\left(\beta r_{b}\right) I_{1}\left(\beta r_{s}\right)}{4 r_{s} K_{1}\left(\beta r_{s}\right)} K_{b}^{2}
$$

The electric field in the portion of the coil that is coupled to the sleeve (neglecting coil resistance) is given by ${ }^{19}$

$$
\underline{E}_{\theta}=\mu_{0} U_{s} \beta r_{b} K_{1}\left(\beta r_{b}\right) I_{1}\left(\beta r_{b}\right) K_{b}\left[\frac{s s_{c}}{s_{c}^{2}+s^{2}} \Omega+j\left(1-\frac{s^{2}}{s_{c}^{2}+s^{2}} \Omega\right)\right]
$$

where $\Omega=\frac{K_{1}\left(\beta r_{b}\right) I_{1}\left(\beta r_{s}\right)}{K_{1}\left(\beta r_{s}\right) I_{1}\left(\beta r_{b}\right)} . \Omega$ is a measure of the amount of coupling between the coil and the sleeve. The field for the uncoupled portion of the coil can be obtained by setting $\Omega$ equal to zero.

Reference 19 did not specifically cover the effects of skin depth or coil resistance. Skin depth gives the effective field and current penetration distance into the surface of a conductor. Since current can flow on both sides of a sheet conductor, the effective conductor thickness for calculating resistance is roughly the lesser of the actual thickness and twice the skin depth. For good conductors the skin depth $\delta=(2 / \mu \omega \sigma)^{1 / 2}$. We can use this method to determine the effective thickness and resistance of both the coil and the sleeve. The resistive electric field of the coil is given by

$$
E_{\text {res }, \theta}=\frac{J}{\sigma_{b}}=\frac{K_{b}}{a_{b} \sigma_{b}}
$$

where $J$ is the current density and $a_{b}$ is the effective coil radius. This resistive field is added to the field determined previously above.

Each coil can be composed of many turns. The current per turn is inversely proportional to the number of turns but the voltage drop is proportional to the number of turns. The skin effect should be mitigated by more turns but this has not yet been incorporated into the model. 
We used a spreadsheet program to estimate the performance of induction launchers based on the current sheet model just presented. As an example, consider the target of Fig. 3 with $0.5 \mathrm{~g}$ of $\mathrm{Li}$ for sleeve material in place of the Flibe. The computations are based on a uniform sleeve thickness so are only approximately correct for this target. The $1 \mathrm{~g}$ target has anouter sleeve radius of $7.5 \mathrm{~mm}$ and a length of $15 \mathrm{~mm}$. The barrel is $5 \mathrm{~m}$ long with a 8.4 $\mathrm{mm}$ effective radius copper coil, 6 phases, 10 turns per coil, and 4 coils per centimeter. We used room temperature material constants and assumed a wave speed of $140 \mathrm{~m} / \mathrm{s}$ requiring a frequency of $9,300 \mathrm{~Hz}$. With a current amplitude of $61 \mathrm{~A}$ and target speed of $50 \mathrm{~m} / \mathrm{s}$, the target acceleration is $1070 \mathrm{~m} / \mathrm{s}^{2}$. The acceleration averages about $1000 \mathrm{~m} / \mathrm{s}^{2}$ throughout the length of the barrel allowing a final target velocity of about $100 \mathrm{~m} / \mathrm{s}$. The heating of the sleeve is $104^{\circ}$ per second which for $0.1 \mathrm{~s}$ of acceleration would result in an acceptable $10^{\circ}$ temperature rise. The phase voltage is $4.7 \mathrm{kV}$. The electrical power delivered to the barrel, due mostly to ohmic heating of the barrel, is $83 \mathrm{~kW}$. This is about $26 \mathrm{~W} / \mathrm{cm}^{2}$ of external barrel surface which could be removed by a cooling water jacket. The power and voltage requirements could reduced about two orders of magnitude by energizing only a small portion of the barrel that the target is in at a given time.

Induction accelerators are more complicated than rail guns but offer a significant advantage of requiring no electrical contact between the barrel and the coils. The fields even provide a centering force for the projectile within the barrel so no physical contact is necessary. A significant mass of conducting material must be included in the sleeve for induction acceleration to be effective. If this sleeve is to enter the reaction chamber with the capsule, it should be made of compatible materials. For example, if lithium is used for the sleeve material for a power plant containing molten Flibe, it will be necessary to provide additional fluorine to combine with the lithium.

\section{CONCLUSIONS AND RECOMMENDATIONS}

Different target injection methods are probably appropriate for different target and power plant designs.

A gas gun is recommended for targets that can support a gas pressure load on one end and can slide along the gun barrel without damage such as the indirect drive target in Fig. 3. For other types of targets, a sabot would be necessary. The detachment of the sabot from the target may exert an impulse to the target. This impulse could degrade target accuracy. The amount of gas required for each target (about 10 to $100 \mathrm{mg}$ ) is acceptable.

An electrostatic accelerator injection system is recommended for use with low mass spherical direct drive targets. No additional materials must be added to the target for propulsion. Since there is no physical contact between the target and the injector there will be no wear of either component during the injection process. However, this lack of physical contact requires feedback control of the target position which must be developed and demonstrated.

An induction accelerator has an advantage of no electrical contact between the target and the injector. Physical contact is not even necessary, so the wear should be minimal. It requires conductive material for the target sleeve $(0.5 \mathrm{~g}$ in the example) which would be a disadvantage for some power plant designs.

A rail gun may be useful for target injection and is a simpler device than an electrostatic accelerator or induction accelerator. It requires electrical contact between the target and the rails and may have a significant wear rate.

Each of these injection methods have advantages and disadvantages. They all have the possibility of working well with certain types of targets. However, the gas gun is the simplest of the devices and appears to have the lowest risk of failure. The gas gun will probably work well with indirect drive heavy ion beam targets as used in HYLIFE-II. The ability of a target injection system to reliably meet target injection requirements should be experimentally verified.

\section{ACKNOWLEDGMENTS}

This work was performed under the auspices of the U. S. Department of Energy by Lawrence Livermore National Laboratory under Contract W7405-Eng-48.

\section{REFERENCES}

1. R. W. Petzoldt and R. W. Moir, Requirements and Feasibility Considerations for Inertial Fusion Energy Target Injection, Tracking, and Beam Pointing, Lawrence Livermore National Laboratory, Livermore, CA, unpublished work.

2. M. J. Monsler, "Laser Fusion: An Assessment of Pellet Injection, Tracking and Beam Pointing," Proceedings of the Third Topical Meeting on the 
Technology of Controlled Nuclear Fusion, Santa Fe, NM, May 1978.

3. W. R. Meier et al., W. J. Schafer Associates, OSIRIS and SOMBRERO Inertial Confinement Fusion Power Plant Designs, DOE/ER/54100-1 (1992).

4. R. W. Moir et al., "HYLIFEII: A Molten-Salt Inertial Fusion Energy Power Plant Design Final Report" Fusion Technology, 25, 5 (1994).

5. R. Kreutz, "Pellet Delivery for the Conceptual Inertial Confinement Fusion Reactor HIBALL;" Fusion Technology, 8, 2708 (1985).

6. L. M. Waganer et al., Inertial Fusion Energy Reactor Design Studies Final Report, McDonnell Douglas Aerospace, DOE/ER-54101 (1992).

7. D. D. Ho, "Target Physics for Heavy Ion Fusion," To be published in the proceedings of the Eleventh Topical Meeting on the Technology of Fusion Energy, New Orleans, LA, June 1994.

8. R. Beeman, Air Gun Digest, DBI Books, Northfield, IL (1977) p. 238.

9. W. L. Johnson and C. D. Hendricks, Electrostatic Levitation and Transport of Laser Fusion Targets, Lawrence Livermore National Laboratory, Livermore, CA, UCRL-83981 (1980).

10. C. D. Hendricks, Levitation, Coating, and Transport of Particulate Materials, Lawrence Livermore National Laboratory, Livermore, CA, UCRL-86117 (1981).

11. R. F. Wuerker, H. Shelton, and R. V. Langmuir, "Electrodynamic Containment of Charged Particles," Journal of Applied Physics, 30, 342 (1959).

12. R. Gomer, Field Emission and Field Ionization, Harvard University Press, Cambridge, MASS (1961) p. 1.

13. W. D. Kilpatrick, A Criteria for Vacuum Sparking to Include both $R$. $F$. and $D C$, University of California Radiation Laboratory, Livermore, CA, UCRL-2321 (1953).

14. A. Y. H. Cho, "Contact Charging of MicronSized Particles in Intense Electric Fields," Journal of Applied Physics (USA), 35(9), 2561-4 (1964).
15. A. D. Sarkar, Wear of Metals, Pergamon Press, New York (1976) p. 39.

16. A. D. Sarkar, Wear of Metals, Pergamon Press, New York (1976) p. 137.

17. F. J. Clauss, "Lubrication of Ball Bearings and Slip Rings Under High Vacuum," Proceedings of a Symposium on Lubrication in Space, Cambridge, MASS, February 7-9, 1962 (N6419952).

18. D. G. Elliott, "Traveling-Wave Induction Launchers," IEEE Transactions on Magnetics, 25,(1), 159 (1989).

19. J. L. He, E. Levi, Z. Zabar, L. Birenbaum, and Y. Naot, "Analysis of Induction-Type Coilgun Performance Based on Cylindrical Current sheet Model," IEEE Transactions on Magnetics, 27(1), 579 (1991).

20. J. D. Jackson, Classical Electrodynamics, 2nd ed., John Wiley \& Sons, New York (1975) p. 298. 